\title{
DESENVOLVIMENTO INDUSTRIAL E POLÍTICAS DE EDUCAÇÃO NA GÊNESE E NA CONSTITUIÇÃO DO ESTADO DE MATO GROSSO DO SUL E NO MUNICÍPIO DE CAMPO GRANDE ${ }^{12}$
}

\author{
Jefferson Carriello do Carmo ${ }^{3}$
}

\section{RESUMO}

O objetivo deste texto é investigar, na gênese e na Constituição do Estado de Mato Grosso do Sul e do município de Campo Grande, o desenvolvimento industrial, no setor secundário, e as políticas de educação para o trabalho, centrando-se na identificação de algumas ocorrências sobre o processo de industrialização nesse setor e nas políticas educacionais oriundas desse processo. As hipóteses que norteiam esse trabalho são duas: que o Governo Federal (Estado) a) gerenciou um "novo" desenvolvimento econômico; b) corroborou para manter o crescimento econômico alicerçado no binômio segurança/desenvolvimento instaurado pela ditadura militar contando com recursos do capital estrangeiro, do empresariado brasileiro e com o Estado como agente econômico, c) contribuiu e fortaleceu o embate político na divisão do Estado do Mato Grosso. Para essas questões postas, verificou-se que o Governo Federal contou com o I Plano Nacional de Desenvolvimento (PND, 1971) e os Plano de Desenvolvimento Econômico-social do Centro-Oeste (PLADESCO, BRASIL, 1973) e II Plano Nacional de Desenvolvimento: programa de ação do governo para região Centro-Oeste, 1975-1979 (SUDECO, BRASIL, 1975). E, por fim, esse desenvolvimento teve como uma de suas estratégias as articulações com as políticas educacionais. Metodologicamente a pesquisa centrou-se no campo teórico-bibliográfico analítico e documental.

Palavras-chave: Políticas de Educação Profissional. Educação e Trabalho. Desenvolvimento da Região Centro-Oeste.

\section{INDUSTRIAL DEVELOPMENT AND EDUCATIONAL POLICIES AT THE BIRTH AND CONSTITUTION OF THE STATE OF MATO GROSSO DO SUL AND IN THE MUNICIPALITY OF CAMPO GRANDE}

\section{ABSTRACT}

The aim of this text is to investigate in the birth and Constitution of the State of Mato Grosso do Sul and of the municipality of Campo Grande, the industrial development, the secondary sector, and educational policies for work; aiming at the identification of some occurrences in the industrialization process, in this sector and the educational policies coming from this process. The hypotheses that guide the study are that the Federal Government (State) a) managed "new" economic development; b) collaborated in order to maintain economic growth founded on the binomial of security/development installed by the military dictatorship counting on resources from foreign capital, from Brazilian businessmen and with the State as economic agent; c) contributed and strengthened the political collision in the division of the State of Mato Grosso. With these questions placed, it was verified that the Federal Government counted on the $1^{\text {st }}$ National Plan for Development (PND, 1971) and the Plans for economic and social development in the midwest (PLADESCO, BRAZIL, 1973) and the $2^{\text {nd }}$ Plan for National Development: program of government action for the mid-west region, 1975-1979 (SUDECO, BRAZIL, , 1975). And, finally, this development had as one of its strategies and articulations, educational 
policies. The research methodology was centered info the field theoretical and analytical bibliographic file.

Keywords: Policies for Professional Education, Education and Work, Development of the Mid-West Region.

\section{Introdução}

O objetivo deste texto é investigar, na gênese e constituição do Estado de Mato Grosso do Sul e do município de Campo Grande, o desenvolvimento industrial no setor secundário e as políticas de educação para o trabalho, centrando-se na identificação de algumas ocorrências sobre o processo de industrialização neste setor e nas políticas educacionais oriundas deste processo.

As hipóteses que norteiam este trabalho são de que o Governo Federal (Estado) a) gerenciou um "novo" desenvolvimento econômico; b) corroborou para manter o crescimento econômico alicerçado no binômio segurança/desenvolvimento instaurado pela ditadura militar contando com recursos do capital estrangeiro, do empresariado brasileiro e com o Estado como agente econômico, c) contribuiu e fortaleceu o embate político na divisão do Estado do Mato Grosso. Para essas questões postas, verificou-se que o Governo Federal contou com o I Plano Nacional de Desenvolvimento (PND, 1971) e os Plano de Desenvolvimento econômico-social do Centro-Oeste (PLADESCO, BRASIL, 1973) e II Plano Nacional de Desenvolvimento: programa de ação do governo para região CentroOeste, 1975-1979 (II PND, BRASIL, 1975). E, por fim, este desenvolvimento teve como umas das suas estratégias as articulações com as políticas educacionais. Metodologicamente a pesquisa centrou-se no campo teórico-bibliográfico analítico e documental.

Vários estudos de diferentes encaminhamentos mostram que, na história econômica e política do Brasil, a participação do Estado precede na forma de orientação e fomento da economia (SUZIGAN, 1988, 2000; BAER, 1977; VARSIANI, BARROS, 1977; FONSECA, 1987; SZMRECSÁNYI, GRAZIERA, 2004, OLIVEIRA, 2008).

No Brasil, no período de 1968-1979, o processo de desenvolvimento e planejamento econômico experimentou um ciclo expansivo e consolidação industrial em que o Estado teve fundamental participação por meio do I PND (1975-1979). A região Centro-Oeste estava entre as que participaram dessa expansão por meio de uma nova fase de investimentos públicos e privados nas indústrias de insumos básicos, de bens de capitais, além de investimentos públicos em infraestrutura. $\mathrm{O}$ objetivo foi completar ${ }^{4} \mathrm{a}$ estrutura industrial brasileira e criar a capacidade de exploração de alguns serviços básicos, com vistas à consolidação de um modelo de capitalismo industrial articulado com o Estado brasileiro e com o capital estrangeiro (OLIVEIRA, 2008, p. 71-92). As principais estratégias industriais para a consolidação utilizadas foram:

Desenvolvimento dos setores de base; abertura de novos campos de exploração de manufaturas; maior impulso ao desenvolvimento tecnológico industrial; impulso ao desenvolvimento da indústria de alimentos, com continuação do esforço de modernização e reorganização de certas indústrias tradicionais; atenuações dos desníveis regionais de desenvolvimento industrial. (BRASIL, 1971, p. 37-41) 
No caso da Região Centro-Oeste, houve dois planos. O primeiro Plano de Desenvolvimento econômico-social do Centro-Oeste e o II Plano Nacional de Desenvolvimento: programa de ação do governo para região Centro-Oeste, 1975-1979, ambos com a finalidade de indicar os objetivos e as diretrizes à dinamização da espacialidade social e econômica dessa região. Esses planos representaram um esforço feito pelo Estado na acumulação de capital e uma diversificação nas estruturas industriais da Região Centro-Oeste, na direção da indústria pesada, que antes não havia acontecido.

Sobre o planejamento do sistema de ensino regional, as estratégias ocorrem por meio dos vários níveis educacionais, e as interferências não só aconteceram por meio do Governo Federal, como também pelos industriais (SENAI, dentre outros) e pelos Organismos Internacionais, Organização das Nações Unidas (ONU) e Organização Internacional do Trabalho (OIT).

\title{
1 Desenvolvimento econômico do estado de Mato Grosso, região Centro-Oeste
}

A economia mato-grossense sempre teve sua base voltada para o setor primário. Essa é uma situação que encontra força para mudanças a partir do I PND, do PLADESCO e do II PND. As grandes preocupações desses planos, dentre outras, foram com o desenvolvimento econômico da região, com a contribuição para o crescimento do Produto Interno Bruto (PIB) brasileiro e melhor distribuição de renda ${ }^{5}$.

O PLADESCO, ao referir-se, no ano de 1968, sobre o crescimento econômico da região, mostra por meio de "dados estatísticos disponíveis que a participação do CentroOeste na composição do Produto Interno Nacional (PIN) foi de apenas 3,3\%, em 1968. Bastante inferior às participações do Sudeste, do Sul e do Nordeste" (Brasil, 1973, p. 83). Os dados estatísticos mostram que os habitantes do Centro-Oeste representavam aproximadamente um percentual de $5 \%$ da população nacional. Esse dado permite ao PLADESCO (BRASIL, 1973, p. 83) estipular a elevação do PIN regional de "3,3 para 5\%, até o fim da década para que se alcance um nível adequado de bem-estar da população e se mantenha equiparada à renda nacional 'per capita'”.

Pela verificação do PLADESCO e II PND, é notável que o setor secundário foi o que veio a contribuir de forma visível para a formação desse crescimento (ABREU, 2001).

\begin{abstract}
A ênfase, para o período considerado, será dada, portanto, ao setor secundário fixando-se como objetivo: "elevar a participação do setor indústria, na formação do $\mathrm{PRB}$, de $5,5 \%$ para $10 \%$, até o fim do período considerado". Tal objetivo implicara em um crescimento, a valores constantes, à razão de $20 \%$ ao ano, taxa viável de ser obtida, considerando-se o estágio incipiente do setor e as potencialidades existentes no setor para as indústrias de transformação de produtos agropecuários e metalurgia de não ferrosos (BRASIL, 1975, p. 83).
\end{abstract}

Os dados revelam que o crescimento da região nesse setor ocorreu por meio do desenvolvimento do setor produtivo secundário contribuindo para a expansão do emprego, expansão dos equipamentos urbanos, do progresso social e da distribuição de renda, metas estipuladas pelo Governo Federal. A estratégia utilizada pelo Governo, dentre outras, foi a espacial. ${ }^{6}$ A cidade de Campo Grande, que ainda não era capital do Estado sul-mato- 
grossense, configurava-se num espaço econômico com vias ao desenvolvimento pelas seguintes razões:

Dotado de razoável infra-estrutura econômica e possuindo um potencial de solos dos mais representativos do Centro-Oeste, sua proximidade dos mercados do Centro - Sul e dos terminais de exportação mais acentuou as razões para sua eleição como área - programa. A capacidade empresarial, sobejamente reconhecida, da classe produtora regional, facilitará sobremaneira a adoção de medidas visando à implantação de indústrias de transformação, bem como à introdução de tecnologia mais avançada na exploração agrícola (BRASIL, 1975, p. 91).

A estratégia setorial do PLADESCO "delineou a integração das economias espaciais pela utilização adequada dos recursos naturais e humanos locais e dos programas econômicos setoriais" (BRASIL, 1973, p. 92). Essa integração passa pelos recursos humanos, particularmente, com o "treinamento e capacitação de mão-de-obra", cuja parceria acontece com a ONU e OIT.

Visando sistematizar e dinamizar os trabalhos nesse importante setor, $\mathrm{O}$ Ministério do Interior está elaborando o Projeto Nacional de Recursos Humanos, envolvendo todos os organismos interessados no assunto, sob a coordenação de um centro específico $(\mathrm{CNRH})$, na Secretaria Geral. Esse projeto, que dá ênfase aos problemas de educação, emprego, capacitação e Migrações internas, a serem considerados em níveis regionais e nacional, se completa com o Programa das Nações Unidas para o Desenvolvimento (PNUD), objeto de recente convênio entre o Governo brasileiro, a ONU e a OIT, com execução a cargo dos Ministérios do Planejamento, do Interior, da Educação e do Trabalho. Conduzindo-se no sentido de se integrar nessa programação maior, ainda em fase de detalhamento, a SUDECO realizará levantamentos básicos primários e desenvolverá ação de treinamento de mão-de-obra, já identificados como necessários e urgentes (BRASIL, 1975, p. 92 - 3).

A participação do Ministério do Trabalho via Programa Intensivo de Formação de mão-de-obra - $\mathrm{PIMBO}^{7}$ foi incisiva quanto aos aspectos educacionais, particularmente das Universidades.

[...] através do Projeto Rondon, estão sendo elaborados os cronogramas e currículos a serem ministrados a partir do primeiro semestre de 1973, abrangendo as áreas de serviços municipais, medicina preventiva, práticas rurais, topografia e manutenção de estradas vicinais (BRASIL, PLADESCO, 1975, p.93).

A educação no Plano de Desenvolvimento Econômico-Social do Centro-Oeste, 1973 faz parte desse treinamento e teve os seguintes objetivos:

1) Desenvolver uma política no sentido de adaptação dos currículos às necessidades econômicas da região, ou seja:

a) a compatibilização com o calendário agrícola;

b) a reformulação de seus conteúdos, não só com a preocupação voltada para atender o setor agrícola, como também para os centros urbanos, na formação de mão-de-obra para as atividades comerciais e industriais. 
2) Melhor atendimento da demanda, considerando:

a) o aumento do número de salas de aulas;

b) a racionalização das atribuições das unidades escolares;

c) a assistência efetiva quanto às condições materiais para o bom atendimento e rendimento dos trabalhos nas escolas.

3) implantação de cursos para formação, treinamento e especialização de professores em curto prazo (BRASIL, 1975, p. 93).

Segundo o documento citado, os objetivos educacionais estão ajustados e programados com os Ministérios da Educação e do Trabalho, nos quais se apoia fundamentalmente a sua execução.

Motivados pela intervenção federal na região e pelo desejo de ampliação dos distritos industriais em um formato mais competitivo para a economia nacional e internacional, o Governo Federal promoveu e patrocinou, juntamente com o Governo de Mato Grosso, em agosto de 1976, em Cuiabá, o 1ํ Simpósio Nacional sobre Distritos Industriais, cujo objetivo foi "promover o encontro dos dirigentes e técnicos do setor industrial de todas as Unidades da Federação para o estudo de medidas que visassem ao aprimoramento dos métodos e técnicas de problemas ligados aos Distritos Industriais" (p. 19). A realização desse simpósio exposto em seu objetivo geral demonstra o interesse dos Governos Federal e Estadual em instituir e aprimorar, sob a ótica do desenvolvimento econômico e social, os distritos industriais no Estado. Isso fica evidente, nas propostas, dos eixos temáticos do evento:

[...] a experiência brasileira de distritos industriais; estímulos aos distritos industriais; o distrito industrial e o desenvolvimento urbano; meioambiente e os distritos federais; recursos humanos e aspectos sociais dos distritos industriais e aspectos institucionais dos distritos industriais. ( $1^{\mathrm{o}}$ SIMPÓSIO..., 1976, p. 32-3).

Oliveira (2003), ao discutir agroindústria e reprodução do espaço na década de 1970, na região Sul do Centro-Oeste, mostra que, no período da implantação dos PND, a indústria não fazia parte dos programas dos investidores locais. Havia uma soma de 643 indústrias no Estado e em 1979, aumentou para apenas 832 estabelecimentos. Esse quadro só se reverteu, como já demonstramos, rapidamente, com a intervenção do Governo Federal por meio do Plano Nacional de Desenvolvimento para o Brasil e algumas regiões especificamente.

\section{Município de Campo Grande após divisão do estado}

O município de Campo Grande está situado no sul da região Centro-Oeste do Brasil, no centro de Mato Grosso do Sul, fundado em 1889 e, com a divisão do Estado, em 1977, passou a ser a capital do Estado. 2011),

Segundo dados históricos do Instituto Brasileiro de Geografia e Estatística (IBGE,

Por recomendação do Excelentíssimo Senhor Presidente da República, General Ernesto Geisel, a Superintendência de Desenvolvimento da Região Centro-Oeste - SUDECO iniciou, em 1975, os estudos básicos visando à divisão do Estado de Mato Grosso. Os resultados, consubstanciados na Exposição de Motivos n. 037 de 24 de agosto de 
1977, foram apresentados ao Chefe do Governo Federal, acompanhados de Anteprojeto de Lei Complementar, criando o Estado de Mato Grosso do Sul. Finalmente, no dia 11 de outubro de 1977, foi solenemente sancionada em Brasília a Lei Complementar n. 31, criando o Estado do Mato Grosso do Sul. Estabelece o seu "Art. 3ํ- A cidade de Campo Grande é a Capital do Estado". Estava então consolidada a velha aspiração dos sul-mato-grossenses e, particularmente, a dos campograndenses. Instalado o Estado no dia 01 de janeiro de 1979, a Capital mato-grossense adquiriu nova feição, passando a apresentar um novo ciclo de progresso, assinalado por maiores estímulos à sua expansão urbana, social, cultural e política. Foi convertida, afinal, como era desejado, em centro das decisões político-administrativas de uma Unidade da Federação.

Nessa divisão do Estado, segundo Zamberlan et al (2010, p. 133), a região sulmato-grossense quanto ao desenvolvimento econômico, com vistas ao processo de industrialização, foi sustentada pelo Plano Nacional de Desenvolvimento (PND). "A preocupação das políticas governamentais até o II PND era de criar, nas regiões não industrializadas, atividades que dessem subsídios à industrialização". No caso, a região onde estava localizada a cidade de Campo Grande, geograficamente, possibilitava o investimento do governo no seu processo de industrialização (BRASIL, 1973, p. 91). Com essa divisão, ocorreram vários programas, cujo objetivo era o desenvolvimento do Estado de Mato Grosso do Sul. Dentre eles e já previsto na Lei Complementar n. 31 de 11/10/1977, o Programa Especial do Desenvolvimento de Mato Grosso do Sul (PROSUL), tendo por objetivo geral e específico:

[...] a promoção do desenvolvimento econômico, além de dois objetivos específicos que vieram no bojo da política nacional de desenvolvimento: $1^{-}$) ampliar a produção de produtos alimentares básicos, como trigo, por exemplo, em grande parte importando, para aliviar a balança comercial da carga de importações, sobrecarregada com a alta do dólar e a crise do petróleo e ampliar a exportação de produtos agropecuários como a soja e a carne; $2^{\underline{o}}$ ) promover a agroindústria no sentido de beneficiar as matérias-primas regionais". (ABREU, 2001, p. 213-4).

No sentido acima indicado, Zamberlan et al. (2010, p. 133), ao referirem-se ao processo industrial na região Centro-Oeste, mais especificamente em Mato Grosso do Sul, acentuam que este

[...] iniciou como modelo de substituição de importações estaduais, criando pequenas indústrias destinadas a suprir a demanda interna por bens de consumo não duráveis. Essa pequena indústria se formou impossibilitada de competir com aquelas localizadas nos grandes centros industriais do país, e talvez, por esse motivo, não houve um crescimento relevante desses setores industriais. No entanto, por pressão dos agropecuaristas, que viam a necessidade de indústrias na região voltadas ao beneficiamento de suas produções, começaram a se formar complexos agroindustriais, o que explica a concentração desse setor em Mato Grosso do Sul em comparação com o país (ZAMBERLAN, et al. 2010, p. 133). 
Com a criação ${ }^{8}$ do Conselho de Desenvolvimento e Integração Sul (CODESUL) e a integração do Estado de Mato Grosso do Sul, a preocupação central foi planejar as áreas mais dinâmicas do Estado para os investimentos, como observadas nos espaços geográficos para a implantação dos Distritos Industriais em que se priorizaram as recomendações emitidas pelos PND. Isso fica comprovado com a criação do Núcleo Industrial de Campo Grande, em 1977, pela Prefeitura Municipal, que o gerenciou até 1979, quando o núcleo passou a ser administrado pelo Estado.

Com a pressão do setor primário e secundário por meio da Federação das Indústrias de Mato Grosso do Sul (FIEMS) ${ }^{9}$ ao final de 1983, os empresários cobraram do governo estadual um posicionamento frente à industrialização do Estado, o que gerou, em março de 1984, a lei n. 440, primeira de incentivos à indústria em Mato Grosso do Sul.

[...] essa lei foi importante na industrialização do Estado, pois incentivou diversos projetos industriais e demonstrou aos investidores, principalmente com a criação do Conselho de Desenvolvimento Industrial, disposição, de ao menos, discutir um processo de industrialização regional com coparticipação do aparelho burocrático. Fora isso, posteriormente foram elaboradas as leis 701, que incentivou 125 projetos e a lei 1239 , que abriu caminho para mais 71 . Essas três leis de incentivo a industrialização fez com que várias unidades agroindustriais fossem implantadas no estado após 1985 e que criaram mais de 3000 empregos diretos, já naquele ano. Foram criadas esmagadoras de soja, moinhos de trigo, frigoríficos, fecularias, laticínios, usinas de açúcar, entre outras. (ZAMBERLAN et al., 2010, p. 129).

Esse fator de crescimento econômico, tendo como destaque o setor secundário, assume um papel relevante para a economia do Estado e para o Município de Campo Grande, porque o fortalecimento da agropecuária no Estado começou a mudar nos anos posteriores. Embora, tenhamos que considerar que a agropecuária e a agroindústria no Estado de Mato Grosso do Sul tem um papel fundamental na contribuição do PIB regional como também no nacional, como mostra a Federação das Indústrias de MS (FIEMS), o município de Campo Grande e outras cidades sul-mato-grossenses vêm despontando como um importante distrito industrial no setor secundário. O Estado continuou inserindo à toda a Região Centro-Sul uma "política de atração", seguida do processo de desconcentração da indústria dos grandes centros. Essa iniciativa parte dos governos Federal, Estadual e Municipal, que oferecem isenções fiscais e de infra-estrutura para a instalação de empresas (FIEMS, SENAI, 2008).

Essa política de atração tem o seu fortalecimento por meio da Lei estadual n. 701, criada em Março de 1987, a qual ampliou os benefícios fiscais dados pela Lei n. 440 e pelo Decreto n. 4.278, que regulamentou esses benefícios quando criou o Conselho do Desenvolvimento Industrial do Estado do Mato Grosso do Sul.

Em 1989, foi criado o Fundo Constitucional de Financiamento do Centro-Oeste (FCO), cuja finalidade é contribuir para o desenvolvimento socioeconômico da região, desempenhando um importante papel na dinamização da economia, como indutor dos investimentos nos setores agropecuário, agroindustrial, industrial, mineral e turístico. Os objetivos norteadores desse fundo são: 
Concessão de financiamentos exclusivamente ao setor produtivo privado; tratamento preferencial às atividades produtivas de pequenos $\mathrm{e}$ miniprodutores rurais e pequenas e microempresas, às de uso intensivo de matéria-prima e mão-de-obra locais, às que produzem alimentos básicos para consumo da população, bem como aos projetos de irrigação, quando pertencentes aos citados produtores, suas associações e cooperativas; preservação do meio ambiente; adoção de prazos e carência, limite de financiamento, juros e outros encargos diferenciados ou favorecidos; conjugação do crédito com a assistência técnica, no caso de setores tecnologicamente carentes; orçamentação anual das aplicações dos recursos; uso criterioso dos recursos e adequada política de garantias, com limitação das responsabilidades de crédito por cliente ou grupo econômico, de forma a atender a um universo maior de beneficiários e assegurar racionalidade, eficiência, eficácia e retorno às aplicações; apoio à criação de novos centros, atividades e pólos dinâmicos, notadamente em áreas interioranas, que estimulem a redução das disparidades intraregionais de renda; proibição de aplicação dos recursos a fundo perdido. (FCO, 2011).

No caso de Campo Grande, após a divisão do Estado de Mato Grosso, novas áreas vieram incorporar o processo de industrialização e seguiam os modelos de desenvolvimento econômico de Distrito Industrial ${ }^{10}$. Estes deveriam funcionar como local central de desenvolvimento e constituído de várias formas de produção. Para que isso viesse ocorrer, o Estado, em um primeiro momento, assumiu todas as formas de investimentos tendo como referência estratégica os propósitos indicados pelos I PND, PLADESCO e do II PND.

Na lógica dos PND, essas áreas deveriam ser construídas estrategicamente para receberem investimentos locais, regionais, estaduais e internacionais, essa era a política posta no PND (Cf. BRASIL, 1975, p. 47-55).

Com as políticas públicas de favorecimento implementadas pelos PND na região Centro-Oeste, o município de Campo Grande constituiu-se num espaço atrativo para empresários locais, nacionais e internacionais, para grandes investimentos no setor secundário, embora, entre as décadas de 1970 e 80, tenha havido duas ocorrências que diminuíram o crescimento econômico do Estado. A crise política no processo de divisão do Estado de Mato Grosso, no final da década de 1970 (BITTAR, 2009) e nos anos de 1980, foi um reflexo da crise que o país enfrentou que favoreceu a redução dos investimentos no Estado e a falta de políticas de desenvolvimento industrial para o setor secundário.

\section{Educação e trabalho no Estado do Mato Grosso e município de Campo Grande após a divisão do Estado}

Segundo Fonseca (1986, p. 255-6), ao referir-se à gênese do ensino industrial no Estado de Mato Grosso, era "inexistente em todo território". Essa imagem só se modificou no ano de 1910 com a criação do primeiro estabelecimento de ensino industrial, "por força do Decreto n. 7.566 de 23 de setembro que mandava criar em cada capital de Estado uma escola profissional, inaugurava a $1^{\circ}$ de janeiro de 1910 a escola de Aprendiz Artífices de Mato Grosso". Cunha (2000, p. 66), ao se referir a essas escolas de aprendizes artífices, afirma que: 
Se a rede de escolas de aprendizes artífices não inovou muito em termos ideológicos e pedagógicos, ao menos no início de seu funcionamento, ela trouxe uma grande novidade em relação à estrutura do ensino, por constituir, provavelmente, o primeiro sistema educacional de abrangência nacional.

Em 16 de fevereiro de 1959, com o aparecimento da Lei n. 3.552, que dava autonomia para a "criação de estabelecimentos de ensino industrial pertencentes ao Ministério da Educação, foi criado na Escola um Conselho de Representantes" que podiam ser ou não indicados pelo governo. Salienta Fonseca (1986, p. 259), ao citar a Lei n. 3.552, de 16 de fevereiro de 1959, que o objetivo dessa escola centrava-se em: a)"proporcionar base de cultura geral e iniciação técnica que permitam ao educando integrar-se na comunidade e participar do trabalho produtivo ou prosseguir seus estudos; b) preparar o jovem para o exercício de atividade especializada, de nível médio".

No Estado, também funcionava a Missão Salesiana, com uma escola Profissional Municipal, o Liceu de Artes e Ofícios São Gonçalo, na cidade de Cuiabá. Em 1945, em Três Lagoas, funcionava a Escola Ferroviária de Três Lagoas, da Estrada de Ferro Noroeste do Brasil, sob a orientação do SENAI. Na cidade de Campo Grande, em 1949, começou a funcionar o SENAI, com os mesmos objetivos e missão postos em sua organização, na década de 1940 (FONSECA, 1986).

Entre as décadas de 1940 e 1970, embora o Brasil vivenciasse um modelo nacional de desenvolvimento, cuja base foi o processo de industrialização (FURTADO, 1969; 1974; 1983), o Estado interveio por meio de mecanismos legais e estruturais formativos enquanto ator principal dos planos, dos projetos e dos programas de investimentos que alicerçaram o desenvolvimento econômico-social. Juntamente com empresariado industrial e as agências multilaterais, estes interferiram nas práticas escolares quanto à concepção da educação para o trabalho tendo em vista as mudanças que estavam ocorrendo nas formas de produção capitalistas e na internacionalização do capital (CUNHA, 1978, MANFREDI, 2002, SAVIANI, 1987, HORTA, 1987).

O II PND, quando se refere ao planejamento econômico, acentua a intervenção estatal no campo educacional, cujo objetivo centra-se na gerência do sistema educativo para o desenvolvimento econômico e social da região. Essa direção tinha por finalidade adaptar os currículos às necessidades econômicas, principalmente, quanto ao setor secundário na formação de mão de obra para as atividades comerciais e industriais.

Nesse período, o planejamento do sistema de ensino buscava adequar as políticas educacionais às necessidades do desenvolvimento econômico nacional e regional, acentuando a preparação para o trabalho. Essas políticas encontravam respaldo das empresas e nos organismos diretamente ligados ao capital, os quais não se preocupavam, de maneira geral, com os aspectos formativos do educando, mas tão-somente com os aspectos operacionais de treinamento, para o exercício da mão de obra qualificada. O sistema educacional, através de suas políticas, vê na escola a responsabilidade da preparação para o trabalho como dimensão formativa do educando. (BOLOGNA, 1967; PEREIRA, 1967). Essa foi uma intenção posta pela Lei n. 5.692/71 que fixa as diretrizes e bases para o ensino de $1^{\circ}$ e $2^{\underline{o}}$ graus. Essa lei instituiu a profissionalização compulsória no ensino secundário (ROMANELLI, 1988; WARDE, 1979, dentre outros). 
Especificamente no caso da Região Centro-Oeste compete advertir que essa lei foi criada em um momento da economia brasileira e tinha como ênfase o crescimento do setor secundário. Nesse setor, "a economia regional apresentou em 1970 um baixo índice de industrialização, uma vez que na composição da renda interna bruta a sua participação foi de apenas $5,5 \%$, e em relação ao produto industrial nacional não chegou a atingir $0,7 \%$ " (BRASIL, 1975, p. 54).

No caso da região Centro-oeste, esse baixo índice de industrialização teve algumas implicações: agilização no processo de urbanização; redefinição das relações entre capital e trabalho, com o surgimento das indústrias de transformação, no ramo alimentício, minerais e não minerais, metalurgia, madeira e mobiliário, têxtil, vestuário, calçados, química e outros ramos que implicou hierarquias ocupacionais. A redefinição das relações entre capital e trabalho no âmbito do sistema produtivo do setor secundário provocou a demanda por técnicos de nível médio e atribuiu-se ao sistema de ensino a função de preparar recursos humanos para o desenvolvimento econômico da região. Os dados oferecidos pelo II PND (BRASIL, 1975, p. 33-8) mostram que, entre os anos de 1970 e 1972, no geral, houve um "aumento" em todos os níveis educacionais, primário, médio, superior e profissional devido à participação preponderante da esfera pública, também houve investimentos em salas de aula e corpo docente. Do ponto de vista das políticas educacionais, os investimentos completavam o ciclo das reformas educacionais dando continuidade a ordem socioeconômica. Segundo Saviani (1987, p. 122)

\begin{abstract}
A Lei $\mathrm{n}^{\mathrm{0}}$ 5.692/71 completa o ciclo de reformas educacionais destinadas a ajustar a educação brasileira à ruptura política perpetrada pelo golpe militar de 1964. E, [...] tal ruptura política constituirá uma exigência para a continuidade da ordem socioeconômica. Considerando-se essa continuidade no âmbito socioeconômico, é compreensível que haja uma continuidade também no que diz respeito à educação.
\end{abstract}

$\mathrm{Na}$ perspectiva dos planos I e o II PND, os objetivos postos quanto ao desenvolvimento econômico, nos seus vários ramos, para a Região Centro-Oeste aconteceram parcialmente. As regiões rurais tiveram menos acesso às escolas e professores, e nessas regiões os professores em sua maioria eram os chamados "leigos". Se considerar os números apresentados pelo governo para a região Centro-Oeste, tal política educacional mostrava-se falaciosa. Em termos de legislação tal lei pressupunha perfeita sintonia entre sistema de ensino e sistema produtivo - tanto em termos quantitativos, quanto em termos qualitativos, de tal sorte que a cada egresso do ensino de $2^{\underline{o}}$ grau correspondesse um emprego definido no mercado de trabalho. Sabemos que, numa sociedade capitalista, a relação entre capital e trabalho e o mercado de trabalho é dinâmica, o que inviabiliza o planejamento de recursos humanos a longo e até mesmo em médio prazo. No caso de um dos produtos desejados pela Lei, que era a "qualificação para o trabalho", isso demanda tempo para o educando estar apto a engajar-se na força de trabalho. Isso, sem levar em conta que os sistemas de ensino não contam com pesquisas de mercado de trabalho atualizadas e fidedignas para informarem um planejamento dessa natureza.

Além disso, vários estudos mostram a oposição entre teoria e prática quanto à operacionalização da Lei n. 5.692/71, via os Pareceres n. 45/72 e n. 76/75, relatando que as escolas não depuseram recursos humanos, físicos, financeiros para adaptarem e readaptarem os cursos que oferecem as necessidades das constantes mudanças oriundas das 
ocupações e profissões, originárias dos constantes avanços da ciência e da tecnologia (WARDE, 1979; FREITAG, 1986; SAVIANI, 1987). Embora sejam visíveis as dificuldades de operacionalizar a Lei n. 5.692/71, o que não pode ser desconsiderado são as formas postas pelos PND quanto ao plano do desenvolvimento econômico e social e do planejamento educacional. Na perspectiva da forma de organização da produção capitalista pelo PND, a intervenção objetiva do Estado em direcionar e planejar o sistema educacional para cumprir a sua função política busca atenuar as transformações socioeconômicas e seus efeitos à estrutura do capitalismo. A sua ação é permanente, sistemática e visa resolver os problemas criados pelo seu próprio desenvolvimento, além de buscar defesas contra os disfuncionamentos do sistema, sem, modificá-lo em sua estrutura. A finalidade desse planejamento constitui-se numa expansão da ideia de planificação do domínio econômico para o campo de ensino; é considerada uma tarefa de técnicos, normalmente colocados fora do campo de influência específica dos educadores, e constitui um dos mecanismos básicos de ampliação da educação enquanto direito social para a cidadania, sendo um dispositivo de garantia para a legitimação do Estado Capitalista (MARHALL, 1967).

No planejamento do sistema de ensino, o Estado busca adequar as políticas educacionais às necessidades do desenvolvimento econômico, acentuando a preparação para o trabalho, que tem como respaldo as empresas e os organismos diretamente ligados ao capital, os quais não se preocupam, de maneira geral, com os aspectos formativos do educando, mas tão-somente com os aspectos operacionais de treinamento, para o exercício da mão-de-obra qualificada. O sistema educacional, através de suas políticas, vê na escola a responsabilidade da preparação para o trabalho como dimensão formativa do educando (CARMO, 2006, p. 147).

Os caminhos para tal preparação são as legislações educacionais, que se expressam principalmente pela expansão do ensino fundamental (SAVIANNI, 1978; 1997) incorporada pelo planejamento educacional (KUENZER; WALTER; CALAZANS, 1990) que mantém uma estreita relação com as necessidades de acumulação do capital (LAUNAY, 1979) revelando uma correlação entre educação e trabalho, cuja finalidade é adaptar a escola ao mundo do trabalho.

Do ponto de vista educacional, na forma pela qual vinha sendo planejado o sistema educacional, pelo PND, a intervenção do Estado tem por finalidade delinear políticas educacionais que visem dar conta dessas mudanças do desenvolvimento econômico e social, não só no âmbito nacional, mas também regional. A Lei n. 5.692/71 foi promulgada para delinear do ponto de vista das políticas educacionais a "profissionalização universal e compulsória para o ensino secundário" tendo em vista a preparação dos recursos humanos para a absorção do mercado de trabalho com vistas aos objetivos socioeconômicos postos pelo I PND.

Outro aspecto relevante, presente nas políticas educacionais nessa relação trabalho e educação, é a presença dos setores empresariais no Estado e em Campo Grande.

Somando-se a uma opção estratégica de desenvolvimento voltada para grandes projetos nacionais, dos quais a Região Centro-Oeste fazia parte, como já observamos, a necessidade de mão de obra em massa motivou a revitalização do PIMBO. Esse programa assume convênios com as empresas a fim de executar a formação profissional, por meio de cursos de duração breve e de conteúdo prático e operacional tecnicista, balizado pelos 
projetos de desenvolvimento e fortalecido pelo Sistema $\mathrm{S}$ e por escolas técnicas da rede federal e empresas privadas e estatais.

Em Campo Grande, o Sistema S está atuando desde 1948, com o SESI, SENAI e o Instituto Euvaldo Lodi (IEL), o qual, criado em 1969 pela CNI, SESI E SENAI, constituise numa associação civil. O fundamento do Sistema $\mathrm{S}$ está nos projetos de reforma do ensino fundamental e médio. Nesse sentido, é possível conceber mediante a Lei n. 5.692/1971 11 que o país objetivava participar da economia internacional, delegando para a educação a preparação dos recursos humanos para a absorção do mercado de trabalho. Ainda na perspectiva da profissionalização compulsória regida pela Lei n. 5692/1971 e pelos Pareceres n. 45/72 e n. 76/75, ofereciam, na mesma escola e com algum nível de integração com a formação geral (sob a denominação de núcleo comum do currículo) e com a formação técnica (sob a denominação de disciplinas específicas).

Teoricamente a educação para o trabalho, tendo em vista o desenvolvimento econômico, justifica-se pela Teoria do Capital Humano, que atuava na perspectiva economicista. Surgida após a Segunda Guerra Mundial, essa teoria, que define a educação como um fator de produção, está relacionada ao modo de produção fordista, no contexto das teorias do desenvolvimento. Essa teoria incorpora em seus fundamentos a lógica do mercado, e a função da escola se reduz à formação dos "recursos humanos" para atender a estrutura de produção (SCHULTZ, 1973a; SCHULTZ, 1973b; LAMARCA, 1978).

Nessa lógica se articulam o sistema educativo e o sistema produtivo tendo em vista que "a educação é o principal capital humano enquanto é concebida como produtora de capacidade de trabalho, potenciadora do fator trabalho. Neste sentido, é um investimento como qualquer outro" (FRIGOTTO, 1989, p. 40-1), ou seja, as ideias que norteiam a teoria do capital humano são a educação, a instrução e o treinamento, com vistas à capacidade de produção. Nas palavras de Frigotto (1989, p. 41).

[...] a idéia de capital humano é uma "quantidade" ou um grau de educação e de qualificação, tomado como indicativo de um determinado volume de conhecimentos, habilidades e atitudes adquiridas, que funcionam como potencializadoras da capacidade de trabalho e de produção. Desta suposição deriva-se que o investimento em capital humano é um dos mais rentáveis, tanto no plano geral do desenvolvimento das nações, quanto no plano da mobilidade individual. (FRIGOTTO, 1989, p. 41)

Resumindo, a capacitação para a produção é a ênfase da teoria do capital humano que se efetiva em torno dos processos educativos e de qualificação humana para responder aos interesses ou às necessidades de redefinição do padrão de acumulação capitalista, no caso da região centro-oeste, do setor secundário. Nesse setor, o processo de qualificação será tão decisivo que, conceitualmente, o trabalho deixará de ser uma atividade humana para transformar-se em capital humano, o que reforça dois entendimentos a respeito do capital: um que envolve os aspectos financeiros, (maquinário, terra, tecnologia etc..) e outro, o capital humano, do qual todos são portadores, podem ser aperfeiçoado constantemente via educação.

Essa capacitação e o seu sentido se tornam mais claros pela noção de investimento, mensurado em termos de número de anos de escolaridade quanto ao tipo de estudo feito e de aprofundamento obtido formalmente ${ }^{12}$. A partir disso, a noção de capital humano propõe 
uma mensuração também dos resultados desse investimento no que se refere ao tipo de estudo e dos anos de escolaridade que representaram custos monetários. E os resultados serão aferidos em forma de aumento de renda pessoal e social. No nível pessoal, a aferição é feita por meio de diferenças nos rendimentos em função do nível de escolaridade atingido.

No âmbito nacional e da região Centro-Oeste, as políticas públicas de educação no período em discussão, no conteúdo de suas propostas, objetivam o desenvolvimento econômico, articulando-se com outras políticas de emprego, de trabalho e de renda: a integração dos programas de qualificação e requalificação.

\section{Considerações finais}

A pretensão, neste texto, foi verificar e examinar, nas décadas de 1970 e 80, o papel ativo do Estado no processo de estruturação e consolidação do setor secundário na região Centro-Oeste e Sul Centro-Oeste, e como esse processo implementa e determina as políticas educacionais em nível regional.

Verificou-se que o Estado brasileiro, a partir da definição de uma estratégia de desenvolvimento social e econômico e do estabelecimento de metas industriais, articulou, no início dos anos de 1970, após as reformas institucionais de meados de 1960, a execução de políticas macroeconômicas expansionistas em várias regiões do Brasil, cuja finalidade era, dentre outras, a formação de capital industrial tendo como estratégia $\mathrm{o}$ desenvolvimento do setor secundário.

$\mathrm{Na}$ segunda metade da década de 1970, o planejamento de um novo ciclo de investimentos públicos e privados nas indústrias de insumos básicos e bens de capital permitiram integrar a estrutura da indústria e consolidar a industrialização do país tendo uma contribuição visível das políticas educacionais do governo e a contribuição do "Sistema S" e de organismos internacionais.

A partir de 1980, o Estado não apenas deixou de orientar como também retardou o desenvolvimento industrial devido à crise do Capital. Esta, por sua vez, gerou uma espécie de indefinição da política desenvolvimentista industrial. Esse período em crise gerou drásticos cortes nos investimentos públicos e privados e reduziu o esforço de incorporação de progresso técnico ao processo de desenvolvimento, tornando-se um desafio, de um Brasil mais cordato, para competir em nível internacional e garantir sua inserção na economia mundial. O grande desafio foi adequar e restabelecer o papel desenvolvimentista do Estado. Isso foi tentado pelo I PND e pela sua execução; em nosso caso de análise, a efetivação ocorreu através do PLADESCO e II PND.

Nos períodos entre as décadas de 1970 e 80, a política educacional foi submetida aos interesses representativos da política de desenvolvimento econômico. O Estado adequou a educação às suas necessidades econômicas e produtivas. As escolas de $1^{\underline{0}}$ e $2^{\underline{o}}$ graus e as legislações educacionais preparavam o aluno para o trabalho, tendo como respaldo as empresas e os organismos internacionais diretamente ligados ao capital, cuja finalidade era os aspectos operacionais de treinamento, para o exercício da mão de obra qualificada. Essa intencionalidade foi mediada pela reforma do ensino de $1^{\underline{0}}$ e $2^{\underline{o}}$ graus mediante a Lei n. 5.692/71 em um momento em que o país tinha como finalidade, dentre outras coisas, aumentar o PIB brasileiro por meio de planos de desenvolvimento econômico e social em várias regiões do país e participar da economia internacional. Para isso atribuiu ao sistema educacional, dentre outras coisas, a tarefa de preparar mão de obra 
qualificada para o "novo" mercado de trabalho que estava nascendo com o desenvolvimento industrial, no setor secundário. Essa preocupação do governo com profissionalização compulsória incluiu todos os níveis educacionais das escolas federais, estaduais, municipais e as particulares incluindo o Sistema $\mathrm{S}$.

\section{Referências}

ABREU, Silvana de. Planejamento governamental: a SUDECO no espaço mato-grossense. 2001. 328f. Tese (Doutorado em Geografia) - Faculdade de Filosofia, Letras e Ciências Humanas da Universidade de São Paulo, São Paulo, 2001. Disponível em: <http://www.teses.usp.br/teses/disponiveis/8/8136/tde-28022002-232232/pt-br.php>.

Acesso em: 12 abr. 2011

BAER, Werner. A industrialização e o desenvolvimento econômico do Brasil. 3. ed. Rio de Janeiro: Fundação Getulio Vargas, 1977.

BENKO, Georges. Economia, espaço e globalização: na aurora do século XXI. 3. ed. São Paulo: Hucitec, 2002.

BITTAR, Marisa. Mato Grosso do Sul, a construção de um estado: poder político e elites dirigentes sul-mato-grossenses. Campo Grande, MS: UFMS, 2009.

BOLOGNA, Ítalo. Formação da mão-de-obra industrial: o caso brasileiro. In: PEREIRA, Luiz. Desenvolvimento, trabalho e educação. Rio de Janeiro: Zahar, 1967.

BRASIL. Lei $n$. 5.692, de 11 de agosto de 1971. Disponível em: <http://www.planalto.gov.br/ccivil_03/Leis/L5692.htm>. Acesso em: 10 abr. 2011.

BRASIL. I Plano Nacional de Desenvolvimento (PND) - 1972/74. Brasília: IBGE, 1971.

. Ministério do Interior. Superintendência do Desenvolvimento da Região CentroOeste. II Plano Nacional de Desenvolvimento (PND): programa de ação do governo para a região Centro-Oeste - 1975-1979. Brasília, 1975.

Lei n. 3.552, de 16 de fevereiro de 1959. Disponível em: <http://www3.dataprev.gov.br/sislex/paginas/42/1959/3552.htm>. Acesso em: 4 abr. 2011.

. Ministério do Interior. Superintendência do Desenvolvimento da Região CentroOeste (SUDECO). Plano de Desenvolvimento Econômico-Social do Centro-Oeste (PLADESCO). Brasília, 1972.

. Ministério do Interior. Superintendência do Desenvolvimento da Região CentroOeste (SUDECO). Plano de Desenvolvimento Econômico-Social do Centro-Oeste (PLADESCO). Brasília, 1973.

BRUSCO, Sebastiano. El concepto de distrito industrial su genesis. In: PYKE, F., BECATTINI, G., SENGENBERGER, W. (Orgs.). Los distritos industriales y lãs pequeñas empresas. I: distritos industriales y cooperacion interempresarial em Italia. Madri: Ministerio de Trabajo y Seguridad Social, 1990.

CARDOSO, Miriam Limoeiro. Ideologia do desenvolvimento Brasil: JK-JQ. 2. ed. Rio de Janeiro: Paz e Terra, 1978. 
CARMO, Jefferson Carriello do. Educação profissional e o Estado intervencionista: velhos problemas ou "novas" soluções? Revista Emancipação, Ponta Grossa, PR, v. 6, n. 1, p. 145-161, 2006.

CUNHA, Luiz Antônio. Educação e desenvolvimento social no Brasil. 3. ed. Rio de Janeiro: Francisco Alves, 1985.

. O ensino de ofícios nos primórdios da industrialização. São Paulo: UNIESP, Brasília, DF: Flacso, 2000.

O ensino profissional na irradiação do industrialismo. São Paulo: UNIESP, Brasília, DF: Flacso, 2005.

FEDERAÇÃO Industrial de Mato Grosso do Sul (FIEMS); Serviço Nacional de Aprendizagem Industrial (SENAI). Economia industrial Mato Grosso do Sul: relatório técnico SENAI, SEBRAE. Campo Grande: FIEMS, SENAI, 2008.

FERNANDES, Florestan. A revolução burguesa no Brasil. Ensaio de interpretação sociológica. Rio de Janeiro: Zahar Editores, 1975.

FONSECA, Celso Suckow da. História do ensino industrial no Brasil. Rio de Janeiro: SENAIS/DN/DPEA, 1986. v. 5.

FONSECA, Pedro Cesar Dutra. Vargas: o capitalismo em construção. São Paulo: Brasiliense, 1987.

FONSECA, Pedro Cesar Dutra; MONTEIRO, Sergio Marley Modesto. O Estado e suas razões: o II PND. Revista de Economia Política, São Paulo, SP, v. 28, n. 1 (109), p. 28-46, jan-mar/2007.

FREITAG, Bárbara. Escola, Estado e sociedade. 6. ed. São Paulo: Moraes, 1986.

FRIGOTTO, Gaudêncio. A produtividade da escola improdutiva: um (re) exame das relações entre educação e estrutura econômico-social capitalista. São Paulo: Cortez, 1989.

FUNDO Constitucional de Financiamento do Centro-Oeste (FCO). Disponível em: <http://www.integracao.gov.br/pdf/fundos/fco/fco_programacao.pdf >. Acesso em: abr. 2011.

FURTADO, Celso. Não à recessão e ao emprego. Rio de Janeiro: Paz e Terra, 1983.

. O mito do desenvolvimento econômico. 3. ed. Rio de Janeiro: Paz e Terra, 1974.

. Um projeto para o Brasil. 5. ed. Rio de Janeiro: Saga, 1969.

HARVEY, David. A produção capitalista do espaço. 2. ed. São Paulo: Annablume, 2006. . O novo imperialismo. São Paulo: Loyola, 2004.

HORTA, José Silvério Baía. Planejamento educacional. In: MENDES, Durval Trigueiro (Coord.). Filosofia da educação brasileira. 3. ed. Rio de Janeiro: Civilização Brasileira, 1987.

IANNI, Octavio. O colapso do populismo no Brasil. 2. ed. Rio de Janeiro: Civilização Brasileira, 1971.

INSTITUTO Brasileiro de Geografia e Estatística (IBGE). Disponível em: <http://www.ibge.gov.br/home/>. Acesso em: abr. 2011. 
KUENZER, Acácia; WALTER, Garcia; CALAZANS, M. Julieta C. Planejamento educacional no Brasil. São Paulo: Cortez, 1990.

LAMARCA, Guillerno et al. La educación burguesa. México: Nueva Imagen, 1978.

LAUNAY, Jean. Elementos para uma economia política da educação. In: DURAND, Jose Carlos Garcia. (Org.). Educação e hegemonia de classe: as funções ideológicas da escola. Rio de Janeiro: Zahar, 1979.

MANFREDI, Silvia Maria. Educação profissional no Brasil. São Paulo: Cortez, 2002.

MARHALL, T. H. Cidadania, classe social e status. Rio de Janeiro: Zahar, 1967.

MARShAlL, A. P. Princípios de economia: tratado introdutório. São Paulo: Nova Cultural, 1985.

MARTINS, Carlos Estevam (Org.). Estado e capitalismo no Brasil. São Paulo: HUCITEC, 1977.

OLIVEIRA, Francisco. Crítica à razão dualista o ornitorrinco. São Paulo: Boitempo, 2008

OLIVEIRA, T. C. M. de. Agroindústria e reprodução do espaço. Brasília: Ministério da Integração Nacional. Campo Grande, MS: UFMS, 2003.

PEREIRA, Luiz. Desenvolvimento, trabalho e educação. Rio de Janeiro: Zahar, 1967.

ROMANELLI, Otaíza de Oliveira. História da educação no Brasil (1930/1973). 10. ed. Petrópolis: Vozes, 1988.

SANTOS, Milton; SOUZA, Maria Adélia A. de; SILVEIRA, Maria Laura (Orgs.). Território: globalização e fragmentação. 4. ed. São Paulo: HUCITEC, 1998.

SAVIANI, Dermeval. Política e educação no Brasil: o papel do congresso na legislação do ensino. São Paulo: Cortez; Autores Associados, 1987. (Coleção Educação Contemporânea). 1997.

A nova lei da educação: LDB trajetória limites e perspectiva. São Paulo: Cortez,

Análise crítica da organização escolar brasileira através das leis 5.540/68 e 5.692/71. In: GARCIA, Walter E. Educação brasileira contemporânea: organização e funcionamento. 3. ed. São Paulo: McGRAW-HILL, 1978.

SIMPÓSIO NACIONAL SOBRE DISTRITOS INDUSTRIAIS CUIABÁ, MT, 1., Anais... Cuiabá, 1976.

SCHULTZ, Theodore W. O capital humano: investimentos em educação. Rio de Janeiro: Zahar, 1973a.

O valor econômico da educação. 2. ed. Rio de Janeiro: Zahar, 1973b.

SUZIGAN, Wilson. Indústria brasileira: origens e desenvolvimento. São Paulo: HUCITEC; Campinas, SP: UNICAMP, 2000.

Estado e industrialização no Brasil. Revista de Economia Política. São Paulo, SP, v. 8, n. 4, p. 5-16, out/nov. 1988. 
SZMRECSÁNYI, Tomás; GRAZIERA, Rui G. (Orgs.). Getúlio Vargas e a economia contemporânea. São Paulo: HUCITEC; Campinas, SP: UNICAMP, 2004.

VARSIANI, Flavio Rabelo; BARROS, José Mendonça de (Orgs.). Formação econômica no Brasil: a experiência da industrialização. São Paulo: Saraiva, 1977. (Série ANPEC de Leituras de Economia).

WARDE, Mirian Jorge. Educação e estrutura social: a profissionalização em questão. 3. ed. São Paulo: Cortez \& Moraes, 1979.

WEINSTEIN, Barbara. (Re) formação da classe trabalhadora no Brasil (1920-1964). São Paulo: Cortez; CDAPH-IFAN - Universidade de São Francisco, 2000.

ZAMBERLAN, et al. Análise da industrialização sul-mato-grossense em fase da industrialização brasileira. Revista Brasileira de Gestão e Desenvolvimento Regional, Taubaté, SP, v. 6, n. 3, p. 114-135, set-dez/2010.

\section{Notas:}

${ }^{1}$ Este texto faz parte da pesquisa "Formas de produção e trabalho e as políticas públicas de educação profissional integrada ao ensino médio no Estado de Mato Grosso do Sul, que está sendo desenvolvida no Programa de Mestrado e Doutorado em Educação na Universidade Católica Dom Bosco (UCDB) e financiada pelo CNPq (Edital MCT/CNPq n. 014/2010 - Universal).

${ }^{2}$ Esse texto foi apresentado no IX Seminário Nacional de Estudos e Pesquisa "História, Sociedade e Educação no Brasil” História da Educação Brasileira: Experiência e Peculiaridade em agosto de 2012. Essa versão foi modificada e teve algumas adaptações.

${ }^{3}$ Pós-Doutor em História Social do Trabalho, Departamento de História da Universidade Estadual de Campinas (UNICAMP). Doutor e Mestre em Educação, área de concentração Educação, Trabalho e Sociedade pela UNICAMP. Atualmente professor e pesquisador do PPGE/UCDB. E-mail jeffccprof@gmail.com

${ }^{4}$ A revolução de 1930 põe fim a um tipo de economia, agrário-exportador e dá início ao tipo urbanoindustrial, cuja base é o desenvolvimento da indústria (OLIVEIRA, 2008, p. 35-60).

${ }^{5}$ Há uma enorme gama de autores, nas mais diversificadas áreas, que fazem uma leitura crítica desses planos mostrando o seu caráter ideológico por trás da ideia de progresso e modernização, desenvolvimento etc. (OLIVEIRA, 2008; IANNI, 1971; CARDOSO, 1978; MARTINS, 1977; FONSECA, MONTEIRO, 2007; FERNANDES, 1975, dentre outros) Essa é uma discussão que vamos enfrentar posteriormente sobre o Estado de Mato Grosso do Sul e a capital, Campo Grande, quanto aos seus aspectos socioeconômico e educacional no que se refere ao ensino médio integrado.

${ }^{6}$ Para o estudo da forma pela qual o Capital apropria-se dos territórios para o processo de acumulação verificar: HARVEY 2004; 2006; BENKO, 2002; SANTOS, SOUZA, SILVEIRA, 1998.

${ }^{7}$ O PIPMO foi criado no governo João Goulart pelo Decreto n. 53.324, de 18 de dezembro de 1963, para treinamento acelerado, de modo que fossem supridos de força de trabalho os diversos setores da economia.

${ }^{8}$ Em 15 de junho de 1961, os governadores dos Estados do Rio Grande do Sul, Santa Catarina e Paraná assinaram convênio criando o Banco Regional de Desenvolvimento do Extremo-Sul (BRDE) e o Conselho Regional de Desenvolvimento do Extremo-Sul (CODESUL), com o objetivo de buscar soluções aos históricos problemas de desequilíbrio regional no País. Em 1992, o estado de Mato Grosso do Sul foi incorporado ao CODESUL, o que fortaleceu a integração e a reivindicação conjunta dos estados mais expostos a um tratamento desigual. A criação do CODESUL visou impulsionar a economia do Extremo-Sul, excluída do processo de industrialização em curso no país, acentuadamente no Sudeste brasileiro. Tradicionalmente, os estados do Sul recebem investimentos em volume menor do que as riquezas geradas por suas atividades econômicas, em decorrência de repasse desequilibrado dos recursos federais. Coube ao 
CODESUL promover o levantamento das necessidades da região, entrosando os planejamentos estaduais, regionais e o nacional. O CODESUL desenvolve, também, relações internacionais, objetivando a integração e o intercâmbio em áreas de mútuo interesse. Com o Mercosul, por exemplo, busca articular uma série de projetos que garantam a inserção competitiva da Região Sul nesse Mercado, em segmentos econômicos como agricultura, indústria, comércio e serviços, infra-estrutura, turismo e tecnologia. Disponível em: <http://www.codesul.com.br/?file=historia.phtml>. Acesso em: 10 abr. 2011.

9 A Federação das Indústrias do Estado de Mato Grosso do Sul (FIEMS) foi criada no dia 6/11/1979, conforme resolução MTb n. 323.051-79.

${ }^{10}$ Para a compreensão do conceito de Distrito Industrial, nos anos de 1970 (BRUSCO, 1990). Para uma análise clássica sobre sistemas de produção capitalista em pequenas unidades e como acontece a organização do trabalho e sua divisão (MARSHALL, 1985).

${ }^{11}$ Essa Lei, no que se refere à profissionalização compulsória, não sobreviveu devido às condições objetivas pertinentes ao ensino público de $2^{\circ}$ grau, no qual não havia articulação entre educação geral e formação profissional, resultando na sua modificação, em 1982, com a Lei n. 7044.

12 A esse respeito, nos anos 1970-1972, na região Centro-Oeste, ver: II Plano Nacional de Desenvolvimento: o Programa de Ação do Governo para a Região Centro-Oeste: 1975-1979 (BRASIL, 1973, p. 33-38).

Recebido: Agosto-2012

Aprovado: Dezembro-2012 